Clemson University

TigerPrints

$3-2020$

Framework for Change: Creating a Diversity Strategic Plan within an Academic Library

Renna Tuten Redd

Alydia Sims

Tara Weekes

Follow this and additional works at: https://tigerprints.clemson.edu/lib_pubs

Part of the Library and Information Science Commons 


\section{Framework for Change: Creating a Diversity Strategic Plan within an}

Academic Library

Renna Tuten Redd*a, Alydia Sims ${ }^{\mathrm{b}}$, Tara Weekes ${ }^{\mathrm{c}}$

${ }^{a}$ Assistant Librarian, Clemson University Libraries, Clemson University, Clemson, SC, USA; ${ }^{b}$ Library Manager, Clemson University Libraries, Clemson University, Clemson, SC, USA; ' Library Manager, Clemson University Libraries, Clemson University, Clemson, SC, USA

rennar@clemson.edu 


\title{
Framework for Change: Creating a Diversity Strategic Plan within an Academic Library
}

\author{
In December 2017, Clemson University's administration via the Assistant Vice \\ President for Strategic Diversity Leadership charged each college and the \\ University Libraries with creating and implementing a diversity strategic plan to \\ align with the ClemsonForward institutional strategic plan and assessment \\ system. Clemson University Libraries answered this charge by creating a \\ Libraries Diversity Plan Working Group (LDPWG), which applied a provided \\ institutional framework to conduct an inventory of current diversity, equity, and \\ inclusion (DEI) initiatives and obtain input, feedback, and support from all the \\ Libraries' faculty and staff as well as the organization and institution \\ administration to create an ambitious diversity strategic plan. The LDPWG \\ worked for sixteen months to create an updated organization mission statement, a \\ sustainable diversity statement, and an accountable roadmap, furthering Clemson \\ University Libraries' DEI initiatives and impact regarding six strategic priority \\ areas: climate and infrastructure, recruitment and retention, education and \\ training, research and scholarship, leadership support and development, and \\ strategic partnerships.
}

Keywords: strategic planning; academic libraries; diversity

\section{Introduction}

\section{Context}

Clemson University is a public land-grant university established in 1889 located in the upstate region of South Carolina. The University is comprised of seven colleges: the College of Agriculture, Forestry and Life Science, the College of Architecture, Arts and Humanities, the College of Behavioral, Social and Health Sciences, the College of Business, the College of Education, the College of Engineering, Computing and Applied Sciences, and the College of Science. The university also has robust cooperative extension programs, a statewide Public Service and Agriculture network, and a 17,500-acre Experimental Forest. 
According to the Clemson University Factbook (Clemson University, 2019), Clemson University serves over 18,971 undergraduate students and over 2,969 graduate students. 19,136 of the total student population self-identifies as white, and 3,636 of the total student population identifies as non-white races (see Figure 1) 5,392 employees are employed by the university. Less than 10 identify as American Indian or Alaskan native, 264 identify as Asian, 511 identify as Black or African American, 245 identify as Hispanic, less than 10 identify as Native Hawaiian or Pacific Islander, less than 10 identify as Non-resident alien, less than 10 identify as two or more races, 116 are unknown, and 4,288 identify as white (see Figure 2).

The Clemson University Libraries consists of one main library (Robert Muldrow Cooper Library), two branch libraries, a Special Collections and Archives, and an offsite facility that houses high-density storage and technical services offices. Cooper Library is by far the largest of the facilities with six floors of collections, study space, classrooms and office spaces. In 2017, there were approximately 82 faculty and staff library employees with 52 employees self-identifying as white, 13 as non-white, and 17 choosing not to disclose (Clemson University, 2019) (see Figure 3).

\section{Climate}

Winning the 2016 NCAA National College Football Championship earned Clemson University national recognition for outstanding athletics and subsequently raised its national profile as an institution of higher education. The university has been recognized as having high rankings for overall and financial value for in- and out-of-state students, active research and internships, and a number one ranking amongst students who love their college (Clemson University, 2019). Clemson's campus was built on the site of the Fort Hill plantation, once of home of former United States Vice President and slavery advocate, John C. Calhoun (1782-1850), at the bequest of his son-in-law, Thomas 
Greene Clemson. Acknowledging these foundations as part of the University's history has been a complicated conversation for many years. The campus has gone from having no recognition to some recognition of the people who were enslaved (and those who later worked by means of prison labor) to forge the economic underpinnings that created the university; however, there is still significant work to be done.

On April 11, 2016, amid both these accolades and debates, bananas were found hanging from a marker acknowledging the African-American slaves who worked the land at Fort Hill. In the days after the incident, the campus climate was tense. While it is important to note that the initial response from University administration was to speak out against the initial incident by stating that "this type of conduct is hurtful, disrespectful, unacceptable and will not be tolerated," (Clements, 2016) many from the campus community were unhappy with the administrative response thereafter. The students responsible for the initial act admitted their involvement on April 12 (Jacks, 2016) and by April 14, the university issued a statement about their continued commitment toward a more diverse and inclusive campus community (Clements, 2016). The responsible party claimed that the incident was not racially motivated and the university administration exonerated them, which resulted in protests that included a 9day sit-in in Sikes Hall (the building which houses the President's offices) (Vasilogrambros, 2016) and the birth of a Twitter hashtag \#beingblackatclemson (2016). As one of the nation's leading public universities, it became important to University Administration to demonstrate that the Clemson family cared for all of its community. As a result, the University dedicated itself to creating "a more diverse and inclusive climate by doubling the number of underrepresented minority faculty, setting goals to increase minority enrollment and requiring all employees to participate in diversity training" (Cary, 2016). 
In December 2017, the Clemson University Office of Inclusion and Equity held a meeting that included all college representatives to the Clemson University President's Council on Diversity and Inclusion. Lee Gill, Chief Inclusion and Equity Officer and Special Assistant to the President for Inclusive Excellence, announced a new initiative for each of Clemson University's colleges to create a diversity plan. The initiative, Strategic Planning for Inclusive Excellence, would be based on six strategic pillars defined in 2015 by Max Allen, Vice-President and Chief of Staff, and Dr. Janelle Chasira, a Fellow of the American Council of Education.

- Education and Training: Education and training experiences to build cultural competencies across the organization.

- Climate and Infrastructure: Creating academic and work environments that effectively support the success of all faculty, staff, and students.

- Recruitment and Retention: Active and aggressive recruitment and retention of a diverse faculty, staff, and student body.

- Research and Scholarship: Building and enhancing opportunities for research and scholarship in diversity fields.

- Strategic Partnerships: Building and supporting strategic partnerships that respect diversity, include diverse groups, and supports the advancement of diversity and inclusion for both.

- Leadership Support and Development: Top-down support for diversity \& inclusion and the creation of a pipeline of culturally competent academic leaders.

\section{Literature Review}

Diversity, equity, and inclusion (DEI) are founding principles of the library and 
information science (LIS) profession. The original 1939 adoption of the American Library Association (ALA) Bill of Rights began with the statement, "Today indications in many parts of the world point to growing intolerance, suppression of free speech, and censorship affecting the rights of minorities and individuals." (Robinson, 1996) This statement is relevant to the current culture and DEI-related research and efforts are still prevalent when reviewing LIS scholarly literature from the last five years. The literature reviewed for this project focused on best practices of building a diversity strategic plan. Cruz (2019) recently published a review of "the current academic literature relating to diversity initiatives in academic libraries," (p. 220), which revealed findings similar to the authors' research regarding numerous resources pertaining to LIS diversity, equity, and inclusion-related definitions, standards, competencies, and initiatives for areas of library work including user services, programming, recruitment, climate assessment, among others. Like Cruz, however, few scholarly resources were found addressing DEI strategic planning within academic libraries.

Some of the most relevant resources regarding DEI strategic planning in academic libraries were found within LIS professional association documents. McManus (2017) wrote of the ALA's recent integration of equity, diversity, and inclusion within the organization's strategic plan, and upon review of that document, the authors noted specific goals and strategies to create "a more equitable, diverse, and inclusive society" (American Library Association, 2017a, p.6). Cruz (2019) also discussed the Association of College and Research Libraries (ACRL) Plan for Excellence (2018) update that incorporated DEI goals and objectives into their organizational strategic plan.

Edwards (2015) stated there are more advantages to developing a stand-alone DEI strategic plan instead of "simply incorporating diversity into a general strategic 
plan" (p.1). This assessment was found to align with the Clemson University Libraries' institutional charge and so directed the search towards more DEI-related resources. Cruz (2019) referenced ALA (2007) as one of the earliest roadmaps for DEI strategic planning in libraries and lists six essential elements to include in a library's diversity plan: a definition of diversity, an assessment of need, a mission or vision, goals or priorities, delegation of responsibilities, and a statement of accountability. Cruz (2019) and Edwards $(2015,2016)$ also pointed to the Association of Research Libraries' (ARL) Spec Kit 319: Diversity Plans and Programs, which contains actual examples of academic library DEI strategic plans, as well as related statements, committee charges, programming, and recruitment activities (Maxey-Harris \& Anaya, 2010). A more recent ARL Spec Kit 356: Diversity and Inclusion was located that provided more academic library DEI strategic plans and activity examples, which heavily influenced the work of the LDPWG committee (Maxey-Harris \& Anaya, 2017).

The work of the group was most informed by the discovery of Edwards' (2015, 2016) articles regarding the recent DEI strategic planning efforts of the University of Montana Mansfield Library in 2011 and 2012. Edwards (2015) recounted the process of developing their academic library DEI strategic plan and discussed the importance of forming a DEI strategic planning committee with broad representation and clearly established expectations. They also offered recommendations to conduct an environmental scan including current library DEI initiatives for assessment purposes; to integrate existing institutional DEI plans and statements; and to ensure administrative and stakeholder feedback and support throughout the strategic planning process. Edwards (2016) also discussed their committee's success with beginning strategic planning with action item ideas and then organizing those accountable ideas into achievable goals. 
Aligning with Edwards' (2015) recommendation to seek and incorporate institutional resources, the search was broadened to include DEI strategic planning in higher education institutions. . Wilson (2015b, 2016), Leon \& Williams (2016), and LePeau, Hurtado, \& Williams (2019) echoed the emphasis on administrative and institution-wide support. Leon and Williams (2016) also affirmed the importance of representative DEI strategic planning committee membership, and they reference Williams' (2013) recommendation of a committee with 10 to 15 members. Clemson University's Assistant Vice President for Strategic Diversity Leadership also recommended Williams, Berger, \& McClendon (2005) and Williams (2007) as resources for all colleges creating their diversity strategic plans.

Damon A. Williams is considered an authority in the field of higher education DEI strategic planning and is cited by many other references. Williams' works often address elements for effective DEI strategic plans, and Wilson (2015a) offered similar advice to include timelines for implementation, accountability measures, and designated resources to support the work. Cruz (2019) echoed these recommended elements within an academic library DEI strategic plan stating that "a well thought out diversity plan with goals, action items, and assessment measures can help libraries define their vision of diversity and lay out steps to achieve it." (p.220).

In addition to general strategic plan elements, Leon \& Williams (2016) recommended "framing the work of the committee to address particular diversity issues on campus" (p.397). Building on this concept Semeraro and Boyd (2017) offered a framework example that higher education DEI strategic plans could use to address categories including "Education and Research, Operations, Diversity and Affordability, Human Resources, Investment, Public Engagement, and Innovation”(p.1311). McManus (2017) and Cruz (2019) also offered similar focus area frameworks for 
academic library DEI strategic plans. McManus referenced the June 2016 ALA Task Force on Equity, Diversity, and Inclusion Final Report which recommended efforts regarding programing, membership and participation, recruitment and retention, education, and administrative priorities and planning. Cruz's literature review also resulted in a framework of five areas that include collections, staffing, services, programming, and culture.

Review of recent scholarly and LIS association literature provided many helpful resources and recommendations regarding the process and elements to include in Clemson University Libraries' diversity strategic planning initiative. Research was also encouraging in demonstrating that the support and framework provided by Clemson University’s Assistant Vice President for Strategic Diversity Leadership would ensure a comprehensive and effective plan to further the Libraries' DEI efforts and impact.

\section{Process}

\section{Group Formation}

Charged by the institution to produce a diversity strategic plan, a call was placed in January 2018 by the interim Dean of the Libraries for volunteers to participate in a new Libraries Diversity Plan Working Group (LDPWG). Thirteen individuals expressed an interest in participating, but it was decided to cap the group at twelve and ensure it was comprised of both faculty and staff from various departments, employee classifications, and self-identities within Clemson University Libraries. Once LDPWG members were informed that they had been selected to serve, several members met with the Assistant Vice President for Strategic Diversity Leadership to gain more understanding about the campus-wide initiative, charge, and framework. Later in the month, the LDPWG held its first meeting where members introduced themselves and shared why they wanted to 
be part of the group's efforts. The LDPWG then selected co-chairs to help guide the work of the group and discussed their charge, timeline, and framework of six strategic priority areas.

\section{Communication}

In discussing ways to move forward with such a large task, the group determined that an internal listserv, a shared Google Drive folder, and a presence on Clemson University Libraries' internal staff intranet, StaffWeb, would be effective tools to facilitate communication within the LDPWG and later with the Libraries at large. The LDPWG used the StaffWeb page to record and share a timeline of their meetings and other activities as well as notable DEI related resources. The LDPWG also sent periodic emails and StaffWeb announcements to all the Libraries' employees to ensure continuous communication and remind them of the StaffWeb page for more information.

\section{Peer Research}

During the first meeting, the LDPWG also decided that knowing what other academic libraries were doing in the area of diversity, equity, and inclusion (DEI) would be extremely valuable. In preparation for their next meeting, members were tasked with familiarizing themselves with ARL SPEC Kit 356: Diversity and Inclusion. The twelve members divided into smaller groups and selected three to four libraries in the publication to review positive and negative aspects of their library diversity statements and websites. Each member was also tasked to read at least one academic library's diversity strategic plan within SPEC Kit 356, with Penn State, Texas A\&M, and Indiana University at Bloomington plans recommended by the co-chairs and other LDPWG members. 


\section{Diversity Statement}

The LDPWG held its second meeting to share reviews of the information presented in SPEC Kit 356. Members discussed elements of other libraries' diversity statements and websites that they thought were useful and sparked discussion and deeper thought (See Figure 4: Institutional Inspiration). Notes of keywords and phrases from the discussion were recorded using poster-sized Post-It Notes. Using these notes, the group started to craft a dedicated Clemson University Libraries diversity statement.

Some of the keywords and phrases noted by the members of the LDPWG were:

- Diversity and inclusion enables us to better serve / best serve

- Individualized and unique experiences

- Unique history, environment, and culture

- Historically aware and compassionate

- Broaden understanding

- Exchange of ideas and perspectives

- Fostering a diverse and inclusive environment

- An environment of respect and inclusion

- Equitable access to information

- Building partnerships

- Welcoming diverse ideas to attain common goals

- Inclusion is essential to continued success

- Diverse local learning communities

- "Foster an internal environment with equal partnership among all employees, based on the principles and practices of courtesy, professionalism, and mutual respect.” (University of Florida George A. Smathers Library, 2014)

- Courageous intellectual exploration

- Maximize the potential of all 
- Respect and include

- Integrity, respect, decency, dignity, and responsibility

- Inclusion is a practice

- Empower employees to help all patrons

The group also discussed some of the key concepts to include:

- The work of diversity and inclusion is essential to continued success in our field and for Clemson University

- The three core values of Clemson (Clemson University, 2017) should be added: integrity, honesty, respect

- The statement applies to employees, collections, spaces, services, and experiences

- This is ongoing work; an iterative process that calls for constant review and refining of policies and procedures

The drafting of the statement also brought up the following questions:

- What is our definition of diversity? Do we include things like citizenship status, socio-economic background, skill set, experiences, etc.? How granular do we get?

- Is there a university-level glossary of terms that we can all refer to?

- What is the Clemson University statement on diversity and inclusion? Where is it?

- What does our library service philosophy say? Does it reflect the same values?

- How do collections fall in to the work of diversity and inclusion? For some, the areas that are most ripe for work are spaces and personnel.

Finally, the group created the following statement: 
Clemson University Libraries seeks to best serve our community through creating a welcoming environment in which diverse ideas and perspectives come together to achieve common goals. We are committed to the practice of inclusion as it is essential to the continued success not only of Clemson University but of the library and information science profession. We embrace Clemson's core values of integrity, honesty, and respect, and add to those the ideals of compassion, dignity, and historical awareness so that Clemson Libraries'staff, collections, spaces, and services inform the interest, information, and enlightenment of all whom we serve.

\section{Inventory of Activities}

After reviewing other libraries' work and crafting a diversity statement, the LDPWG agreed that they needed to know what activities and initiatives Clemson University Libraries had recently undertook in order to determine what to include in the diversity strategic plan. Utilizing the six strategic priority areas provided in the Clemson University diversity strategic plan framework, members of the LDPWG elected to focus on two each. Each subgroup worked to create an inventory of activities and initiatives that the Libraries had sponsored, co-sponsored, or participated in within the past three to five years pertaining to climate and infrastructure, recruitment and retention, education and training, research and scholarship, leadership support and development, and strategic partnerships. (See Table 1: Strategic Priority Examples of Activities) The inventory was recorded in a Google Sheets document online so that everyone in the LDPWG could contribute information.

While some activities were easy to identify, such as hosting the International Student Welcome Reception or providing a workshop on unconscious bias for the Libraries' employees, others were not so simple and questions arose. Should things the 
Libraries have participated in that are actually "owned" by another entity on campus be recorded, such as providing a library orientation to participants of programs designed to help underrepresented groups in STEM disciplines? Also, it became evident early on that the Libraries did a lot of ad hoc programming with different offices and groups on campus but did not have a single person who was responsible for coordinating who to work with and how.

\section{Creating Goals, Objectives, and Action Items}

Once the LDPWG had an understanding of what kind of activities and initiatives the Libraries had recently participated in, the group decided that the next step should be to create a list of potential activities to expand upon what had already been done as well as explore new opportunities. The LDPWG invited colleagues within the Libraries who serve on some of the Clemson University President's Commissions (the Commission on the Status of Women, the Commission on Black Faculty and Staff, the LGBTQ Commission, and the Commission on Latino Affairs) to participate in this exercise at their next meeting.

During that meeting, the co-chairs set up the room with large Post-It Note posters labeled with each of the six strategic priority areas on the walls and gave all participants small pads of Post-It Notes to write DEI activity and initiative ideas. After the group had exhausted and written their ideas, each member stuck their ideas on the posters labeled with the strategic priority area they thought the activity might support. Participants also had stickers to mark and endorse others' ideas. Once the group finished posting, the co-chairs discussed each idea. The group identified similar ideas and consensus areas, reassigned poorly categorized ideas to a more related strategic priority area poster, and recorded ideas that arose from this process. After the meeting, 
the posters and notes were photographed and transcribed for future steps in the strategic planning process.

Soon after, Clemson University's Assistant Vice President for Strategic

Diversity Leadership created and shared a spreadsheet to record the diversity strategic plans of each college and the Libraries. Grouped by the framework strategic priority areas, each section required at least one goal associated with that strategic priority area coupled with related objectives and action steps as well as an estimated time frame for the completion of each objective. Also included were fields identifying potential internal and external partners, existing baseline data, and proposed metrics to assess the success of each objective.

Utilizing this strategic plan spreadsheet, the LDPWG co-chairs met to refine and synthesize the ideas generated from that previous meeting into the provided format. The co-chairs, other LDPWG members, and President's Commissions representatives of the Libraries then met several times to craft goals, measurable objectives, and appropriate objective timeframes as well identify existing baseline data and potential partners and assessment metrics. The co-chairs also met periodically with the Assistant Vice President for Strategic Diversity Leadership as well those working on college diversity strategic plans to obtain recommendation and feedback as the LDPWG continued their work.

\section{Input and Feedback}

As the LDPWG continued to form a draft diversity strategic plan, the framework was presented to all employees of the Libraries with request for additional activity and initiative ideas. With the support of the new Dean of Clemson University Libraries, the co-chairs created a presentation that highlighted how the development of a diversity strategic plan within the Libraries was not just an isolated effort but a campus-wide 
initiative that involved each of Clemson University's colleges and would also expand to include divisions, such as Student Affairs, Athletics, and Information Technology. The presentation also shared the six strategic priority areas and examples of activities that might fall under each. The members of the audience were then invited to write down any ideas they had on pads of Post-It Notes located on each table and stick those ideas on sections of the room walls labeled with the strategic priority area they thought their idea might fall under, mimicking the initial LDPWG brainstorming session. The cochairs presented a tour of the LDPWG StaffWeb page to highlight communication of the group's activities and DEI resource list as well as demonstrate an online and anonymous option for people to provide their ideas and feedback.

Following the meeting and a period of time to allow for online input, the cochairs incorporated the activity and initiative ideas and other feedback from the Libraries' employees into the draft diversity strategic plan. The draft was then presented to the Clemson University Libraries' Dean and Leadership Team for additional input and feedback, and that resulting draft was then published on the LDPWG StaffWeb page with accompanying solicitation emails and announcements for final input and feedback from all Clemson University Libraries' employees. The response to the draft diversity strategic plan was very complimentary and produced a few more constructive comments to consider and incorporate into the plan.

\section{Results}

All of these activities ultimately resulted in a Clemson University Libraries' diversity strategic plan that was approved by the Dean and submitted for review and approval from the Assistant Vice President for Strategic Diversity Initiatives and Clemson University Provost. Given that each college as well as the Clemson University Libraries was tasked with creating a diversity strategic plan, the Assistant Vice President for 
Strategic Diversity Initiatives worked within the Campus Labs institutional assessment software system to create a template of goals, objectives, action items, baseline data, metrics, timelines, partners, and results that aligned with the previously shared spreadsheet. Within this diversity strategic plan template, goals could be linked between colleges and also between different strategic initiatives, including the ClemsonForward strategic plan. Using all of the information and feedback gathered from the LDPWG activities that took place during the 2018 calendar year, the co-chairs completed the LDPWG charge by entering the Clemson University Libraries' diversity strategic plan into the Campus Labs system and template for the 2019 calendar year.

The following are examples of Libraries' goals, objectives, timeframes, action steps, baseline data, metrics, and related ClemsonForward goal for each of the six strategic priority areas.

\section{Climate and Infrastructure}

Goal: Provide more inclusive facilities for Clemson Libraries patrons and employees Objective 1: Implement at least one change per year to provide more inclusive facilities for Clemson Libraries patrons and employees

Start Date: January 1, 2019

End Date: December 31, 2026

Action Steps: Assess and improve: accessibility of pathways and emergency exits; inclusiveness of décor (art work, portraits, room names, etc.); privacy of video phone; gender-neutral and family-inclusive restrooms; furniture for various body sizes and adaptability

Baseline Data: Limited to ad hoc improvements Metrics: One change implemented per year 
ClemsonForward Related Goal: Living Environment - Nurture a climate of diversity, inclusion, and respect.

\section{Education and Training}

Goal: Increase intercultural competence of Clemson Libraries employees

Objective 1: Provide Clemson Libraries employees at least two intercultural competence workshops each year to apply to workplace relations and public services Start Date: January 1, 2019

End Date: December 31, 2026

Action Steps: 1) Jan 2019 - Dec 2020: Collaborate with campus organizations to identify, offer, and possibly adapt existing training, 2) Jan 2021 - Dec 2026: Utilize the Intercultural Development Inventory results to develop, provide, and market at least two intercultural competence and inclusion training workshops each year to apply to workplace relations and public services with periodic assessment to determine and implement improvements to curriculum and methodologies.

Baseline Data: Ad hoc workshops being offered Metrics: Two annual workshops provided and marketed; pre- and post-training assessments

ClemsonForward Related Goal: Living Environment - Nurture a climate of diversity, inclusion, and respect.

\section{Leadership Support and Development}

Goal: Increase communication, encouragement, and funding to support a culture of diversity and inclusion 
Objective 1: Establish, maintain, and communicate financial and work time support for all employees to participate in diversity and inclusion-related training, events, conference presentations, and publications

Start Date: April 1, 2019

End Date: December 31, 2026

Action Steps: 1) Establish and maintain financial support for all employees to participate in diversity and inclusion-related trainings, events, conference presentations, and publications. 2) Establish and maintain a policy and communication method to inform employees of financial and work time support to participate in diversity and inclusion-related trainings, events, conference presentations, and publications.

Baseline Data: Ad hoc work time support

Metrics: Establishment of organization policy and funding

ClemsonForward Related Goal: Living Environment - Nurture a climate of diversity, inclusion, and respect.

\section{Recruitment and Retention}

Goal: Increase diverse representation within the Clemson Libraries workforce Objective 1: Assess current diverse representation of workforce and related recruitment requirements and efforts

Start Date: January 1, 2020

End Date: June 30, 2020

Action Steps: 1) Compare current demographic data of the Clemson Libraries workforce with the current ALA Member Demographics Study data, gathered biennially, to establish gap and goals 2) Assess existing systems of recruitment requirements and search committee trainings. 
Baseline Data: 2018 Clemson University workforce demographic data found in the Clemson University Interactive Fact Book and the 2017 ALA Demographic Study Metrics: most recent demographic data ClemsonForward Related Goal: Living Environment - Increase diversity all across campus.

\section{Research and Scholarship}

Goal: Increase Clemson Libraries resources to support research related to diversity and inclusion

Objective 1: Increase Clemson Libraries' current collections pertaining to diversity and inclusion by at least 40 titles each year

Start Date: July 1, 2019

End Date: December 31, 2026

Action Steps: 1) Conduct a collection analysis to determine representation and publication age gaps of resources pertaining to diversity and inclusion. 2) Create a collection development policy and secure funding to increase collections resources that pertain to diversity and inclusion and that represent diverse authors, illustrators, subjects, and perspectives. Create, provide, and require diversity selection training for personnel working in collection development. 3) Implement collection development policy and annually assess collection development training for diversity and inclusion and improve as needed. 4) Add 40 titles annually

Baseline Data: Ad hoc ordering but no formalized assessment, funding, policy, or procedures

Metrics: Number of titles added each year

ClemsonForward Related Goal: Research - Refocus research mission and increase funding; raise research expectations and reward research excellence. 


\section{Strategic Partnerships}

Goal: Establish a Student Advisory Board with diverse representation of the student body

Objective 1: Establish and maintain a Student Advisory Board with students from diverse populations

Start Date: January 1, 2020

End Date: December 31, 2026

Action Steps: 1) Establish a Library Student Advisory Board and bylaws that encourage diverse student representation. 2) Communicate with Clemson University student organizations devoted to diverse populations and issues to encourage student participation in Clemson Libraries' advisory organization and activities.

Baseline Data: Non-existent

Metrics: Establishment of Student Advisory Board with bylaws and outreach efforts to encourage diverse representation; demographics of board

ClemsonForward Related Goal: Living Environment - Nurture a climate of diversity, inclusion, and respect.

\section{Discussion}

Developing Clemson University Libraries' diversity strategic plan required substantial time, effort, and involvement. The Libraries now have clear goals, action items, and accountability to continue progressing the organization and Clemson University towards being more diverse, inclusive, and equitable, but there were many obstacles to navigate and overcome. Agreeing on methods and language to communicate the Libraries' value of DEI, obtaining an initial assessment, working within a required framework, and ensuring inclusion as well as administrative support throughout the process all presented challenges, but these impediments were ultimately beneficial to creating a sustainable 
strategic plan.

\section{Value of Language}

As the LDPWG began the work, there was much discussion about how to communicate the value of diversity, equity, and inclusion. The Working Group decided to create a dedicated diversity statement to direct the work as well as all Clemson University Libraries, and this decision was later affirmed by request of the Dean to publicly communicate a diversity statement. The Assistant Vice President for Strategic Diversity Initiatives also highly recommended updating the Clemson University Libraries' overall mission statement to include shared value of diversity, equity, and inclusion, which was again supported by the LDPWG and Dean.

Once the method(s) were determined, the next challenge was agreeing on language while crafting both statements. The LDPWG sought feedback from the Office of Inclusion and Equity regarding the use of a list of possible identities within draft statements (i.e. gender, sexuality, race, religion, socioeconomic status, etc.) and received the recommendation to use the phrase "backgrounds, cultures, and identities" instead of an exhaustive and ever-changing list. The LDPWG also sought feedback from all Clemson University Libraries employees to finalize the proposed mission statement update, which resulted in very helpful feedback such as the removal of "regardless" before that phrase and other semantic improvements. The proposed mission statement was heavily edited in response to the employee feedback as well as that of the Dean, and it ultimately resulted in a slight but powerful modification to include the words "inclusive" and "all" to communicate the Libraries" value of those concept and constituents. 


\section{Inclusion in the Process}

Having an inclusive process to involve as much employee input as possible presented challenges but undoubtedly with great benefit. The LDPWG sought feedback from all Clemson University Libraries employees throughout the diversity strategic plan process, which required more time and effort but allowed incorporation of additional ideas and ensured employee support of a plan they helped to develop.

The LDPWG also experienced issues with the inclusion and involvement of a large number of people. The LDPWG started with twelve members representative of diverse units, positions, classifications, and various identities. While this group size provided multiple perspectives during discussions, it also often hindered reaching consensus for meetings and during discussions. The Working Group later expanded to include the Libraries' President's Commission members which contributed valuable input while making it more difficult to coordinate meetings and agreements. The LDWGP expansion as well as that of the original charge timeline triggered a co-chair decision to ask members to reevaluate their work commitments and their ability to contribute to bi-weekly meetings for the remaining $6+$ months of work. This resulted in several LDPWG members declining to continue membership with the Working Group and with improvements to the LDPWG work processes after a reduction in number.

\section{Initial Inventory and Assessment Data}

A particular area of work that required the input of all Clemson University Libraries' employees was in gathering an initial inventory of previous and in-progress DEI initiatives as well as baseline assessment data. The LDPWG found that the organization was involved in many DEI related activities, but these efforts had never been communicated and compiled into a comprehensive record. Likewise, identifying and assembling a list of existing relevant assessment data required inquiries of employees 
throughout the Libraries as well as the Office of Inclusion and Equity and other Clemson University entities. Clemson Libraries has recently hired an Assessment Librarian, whose work will make gathering DEI-related information of this sort easier in the future.

\section{Fitting in the Framework}

The LDPWG is extremely grateful that Clemson University's Assistant Vice President for Strategic Diversity Initiatives provided a framework for the diversity strategic plan, although visualizing and articulating the Libraries' work into the requirements of that framework was difficult at times. The framework's six strategic priority areas were instrumental in ensuring and organizing a comprehensive plan, but there were also additional specific recommended activities within those strategic priority areas that were created with academic college applications primarily in mind, such as diverse course offerings and curriculum experiences or direct recruitment of underrepresented students to the University. The LDPWG often had to seek input, adaptation, and approval of diversity strategic plan items and assessments that better aligned with work as library and information science professionals.

\section{Importance of Administrative Support}

A final and crucial challenge faced by the LDPWG was obtaining administrative support. Clemson University Libraries' diversity strategic planning process was initiated and supported by University administration and the Assistant Vice President for Strategic Diversity Initiatives. University financial support of diversity strategic plans has been promised, but actual committed budgets are vague in what can be applied to fulfill plan action items and objectives.

Likewise, plan approval and monetary support from the Libraries' 
administration has been difficult to obtain due to turnover of the Dean position during this process. This vacancy did allow the LDPWG to influence the search process to hire an administrator who demonstrates a commitment to diversity, equity, and inclusion, but the strategic planning work, diversity plan timelines, and budgeted organization funds have been delayed as a result.

\section{Conclusion}

Overall, Clemson University Libraries' diversity strategic planning has resulted in numerous, tangible products and goals that will guide the organization's commitment to DEI going forward. The Libraries' administration and the Assistant Vice President for Strategic Diversity Leadership have praised the LDPWG's efforts and acknowledged the plan's ambitiousness; both have also committed to ensuring there is proper and sustainable funding. The final solicitation of feedback from all Clemson University Libraries employees confirms the success of the process, as one respondent wrote: "All in all, beautifully and thoughtfully constructed plan! So proud of y'all and proud to be a part of a library system that is committing itself to diversity." Response from LDWPG state and national scholarship activities has also been positive and served as affirmation. The 18 months of work has resulted in a robust strategic plan to improve Clemson University Libraries' diversity, equity, and inclusion initiatives and impact, and a standing Diversity Committee has been established to implement and oversee the plan with organization and institution support and accountability.

The authors of this paper would like to thank the Diversity Plan Working Group: Rodger Bishop, Lisa Bodenheimer, Brenda Burk, Robin Chambers, Jan Comfort, Lita Davis, Lili Klar, Nashieli Marcano, Josh Morgan, Ed Rock, Suzanne Rook-Schilf, and Derek Wilmott. We 
would also like to thank Altheia Richardson for her guidance and Cierra Townson and Jenessa McElfresh for their input.

\section{References}

American Library Association (2007). Strategic planning for diversity. Retrieved from http://www.ala.org/advocacy/diversity/workplace/diversityplanning

American Library Association (2017a). Retrieved from

http://www.ala.org/aboutala/sites/ala.org.aboutala/files/content/governance/StrategicPlan Strategic\%20Directions\%202017_Update.pdf

American Library Association (2017b). Member Demographics Study. Retrieved from http://www.ala.org/tools/research/initiatives/membershipsurveys

Association of College and Research Libraries Plan for Excellent (2018). Retrieved from http://www.ala.org/acrl/aboutaclr/strategicplan/stratplan

Cary, N. (2016, June 3). Emails: Students claimed Clemson banana incident not racist. Greenville News Online Retrieved from https://www.greenvilleonline.com/story/news/education/2016/06/03/emails-studentsclaimed-clemson-banana-incident-not-racist/85291820/

Clements, J. P. (2016). Campus message from President Clements regarding university diversity and inclusion programs. Retrieved from https://blogs.clemson/inside-news/campusmessafe-from-president-clements-regarding-university-diversity-and-inclusionprograms/

Clemson University. (2019). Interactive Factbook. Retrieved from https://www.clemson.edu/institutional-effectiveness/oir/factbook/

Clemson University. (2019). Rankings and Brags. Retrieved from https://www.clemson.edu/about/rankings.html 
Clemson University. (2017). Student Affairs Code of Conduct. Retrieved from

http://www.clemson.edu/studentaffairs/student-handbook/code-of-

conduct/student_code_of_conduct.pdf

Cruz, A. M. (2019). Intentional integration of diversity ideals in academic libraries: A literature review. The Journal of Academic Librarianship, 45(3), 220-227. doi:10.1016/j.acalib.2019.02.011

Edwards, J. B. (2015). Developing and implementing a diversity plan at your academic library. Library Leadership \& Management (Online), 30(2), A1.

Edwards, J.B. (2016). Diversity plans for academic libraries: An example from the University of Montana. Library Leadership \& Management, 29(2), 1-15.

Jacks, A. (2016). Message to campus from VP to Student Affairs Almeda Jacks regarding campus incident/meeting. Retrieved from https://blogs.clemson.edu/insidenews/message-to-campus-from-vp-of-students-affairs-almeda-jacks-regarding-campusincidentmeeting/

Leon, R. A., \& Williams, D. A. (2016). Contingencies for success: Examining diversity committees in higher education. Innovative Higher Education, 41(5), 395-410. doi:10.1007/s10755-016-9357-8

LePeau, L. A., Hurtado, S. S., \& Williams, L. (2019). Institutionalizing diversity agendas: Presidents' councils for diversity as mechanisms for strategic change. Journal of Student Affairs Research and Practice, 56(2), 123-137. doi:10.1080/19496591.2018.1490306

Maxey-Harris, C., \& Anaya, T. (2010). Spec kit 319: Diversity plans and programs.

Washington, DC: Association of Research Libraries. Retrieved from https://publications.arl.org/Diversity-Plans-and-Programs-SPEC-Kit-319/

Maxey-Harris, C., \& Anaya, T. (2017). Spec kit 356: Diversity and inclusion. Washington, DC: Association of Research Libraries. Retrieved from https://publications.arl.org/Diversity$\underline{\text { Inclusion-SPEC-Kit-356/ }}$

McManus, A. (2017). Thoughts on equity, diversity, and inclusion in reference and user services. Reference \& User Services Quarterly, 56(4), 226-227. 
Robbins, L. S. (1997). Censorship and the American library: The American Library Association's response to threats to intellectual freedom, 1939-1969. Westport, CT: Greenwood Press.

Semeraro, E., \& Boyd, N. M. (2017). An empirical assessment of administration and planning activity and their impact on the realization of sustainability-related initiatives and programs in higher education. International Journal of Sustainability in Higher Education, 18(7), 1311-1330. doi:10.1108/IJSHE-03-2016-0047

University of Florida George A. Smathers Library. (2014). Strategic Directions. Retrieved from https://cms.uflib.ufl.edu/portals/communications/Strategic-directions-complete.pdf

Vasilogambros, M. (2016, April 15) Five Arrested in Clemson University Racism Protests. The Atlantic. Retrieved from https://www.theatlantic.com/national/archive/2016/04/clemsonuniversity-arrests/478455/

Williams, D. A. (2007). Achieving inclusive excellence: Strategies for creating real and sustainable change in quality and diversity. About Campus, 12(1), 8-14. doi:10.1002/abc.198

Williams, D. A. (2013). Strategic diversity leadership: Activating change and transformation in higher education (First ed.). Sterling, Virginia: Stylus Publishing.

Williams, D. A., Berger, J. B., \& McClendon, Shederick A. (2005). Toward a model of inclusive excellence and change in postsecondary institutions. Association of American Colleges and Universities. Retrieved from https://www.aacu.org/sites/default/files/files/mei/williams_et_al.pdf

Wilson, J. L. (2015a). Maximizing impact: purposefully incorporating diversity efforts within postsecondary systemwide and institutional strategic plans. Planning for Higher Education, 43(2), 15+. Retrieved from https://link.galegroup.com/apps/doc/A410400824/AONE?u=clemsonu_main\&sid=AON $\underline{E \& x i d=2 \mathrm{~d} 0405 \mathrm{ee}}$

Wilson, J. L. (2015b). Presidential plans: new college presidents and diversity efforts. Planning for Higher Education, 44(1), 76+. Retrieved from 
https://link.galegroup.com/apps/doc/A449344847/AONE? $\mathrm{u}=\mathrm{clemsonu}$ main\&sid=AON

\section{$\underline{E \& x i d=f 09 b 559 c}$}

Wilson, J. L. (2016). Public institution governing boards: the invisible key factor in diversity planning efforts in higher education. Planning for Higher Education, 44(4), 58+. Retrieved from https://link.galegroup.com/apps/doc/A471001702/AONE? $\mathrm{u}=\mathrm{clemsonu}$ main\&sid=AON $\underline{\text { E\&xid }=6 \operatorname{ac} 67239}$

Table 1. Strategic Priority Examples of Activities

\begin{tabular}{|l|l|}
\hline Strategic Priority & Examples \\
\hline Education and & - $\quad$ Workshop for library employees on unconscious bias \\
Training & $\bullet \quad$ "Reclaiming Our Ancestry" genealogy workshop \\
& hosted as part of Black History Month \\
\hline Climate and & Creating gender-neutral bathrooms \\
Infrastructure & \\
\hline
\end{tabular}




\begin{tabular}{|l|c|}
\hline Recruitment and & $\bullet \quad$ Advertising open student positions to student \\
& organizations of underrepresented groups \\
\hline Research and & Membership in the ACRL Diversity Alliance \\
Scholarship & "Documenting the African-American Experience at \\
\hline Strategic & Clemson" digital collection \\
\hline Partnerships & No recorded activities in this area \\
\hline Leadership Support & No recorded activities in this area \\
\hline
\end{tabular}

Figure 1. Racial Identity Among Students at Clemson University

\section{Racial Identity Among Students at Clemson University}

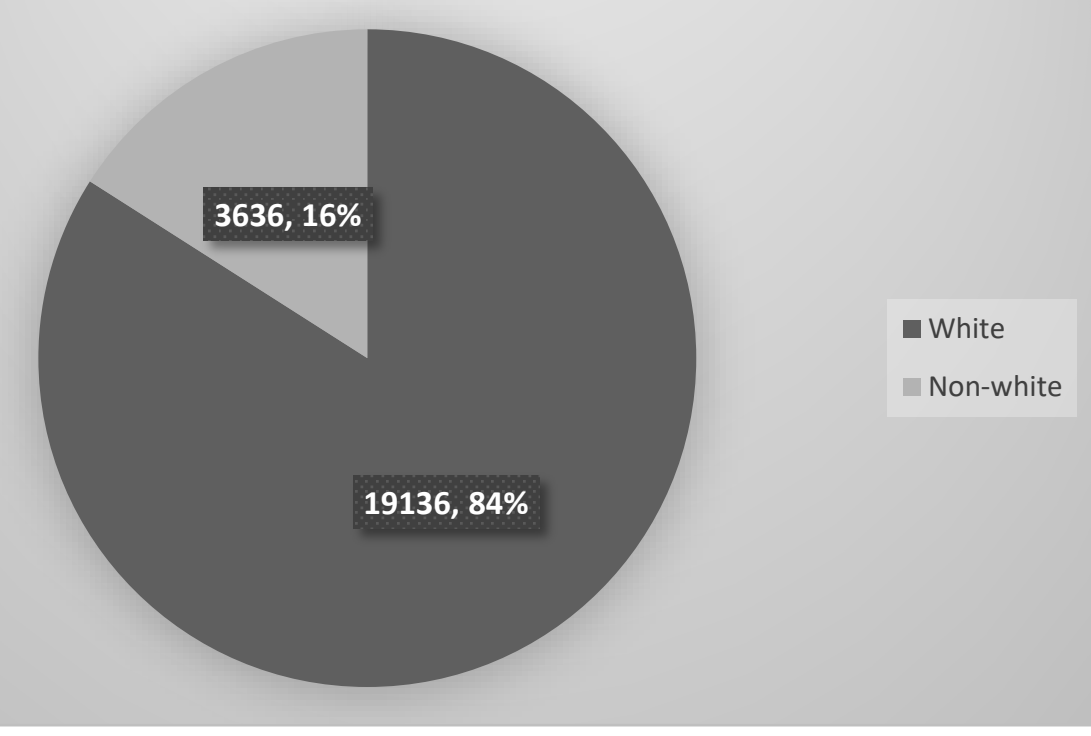


Figure 2: Racial Identity Among Employees at Clemson University

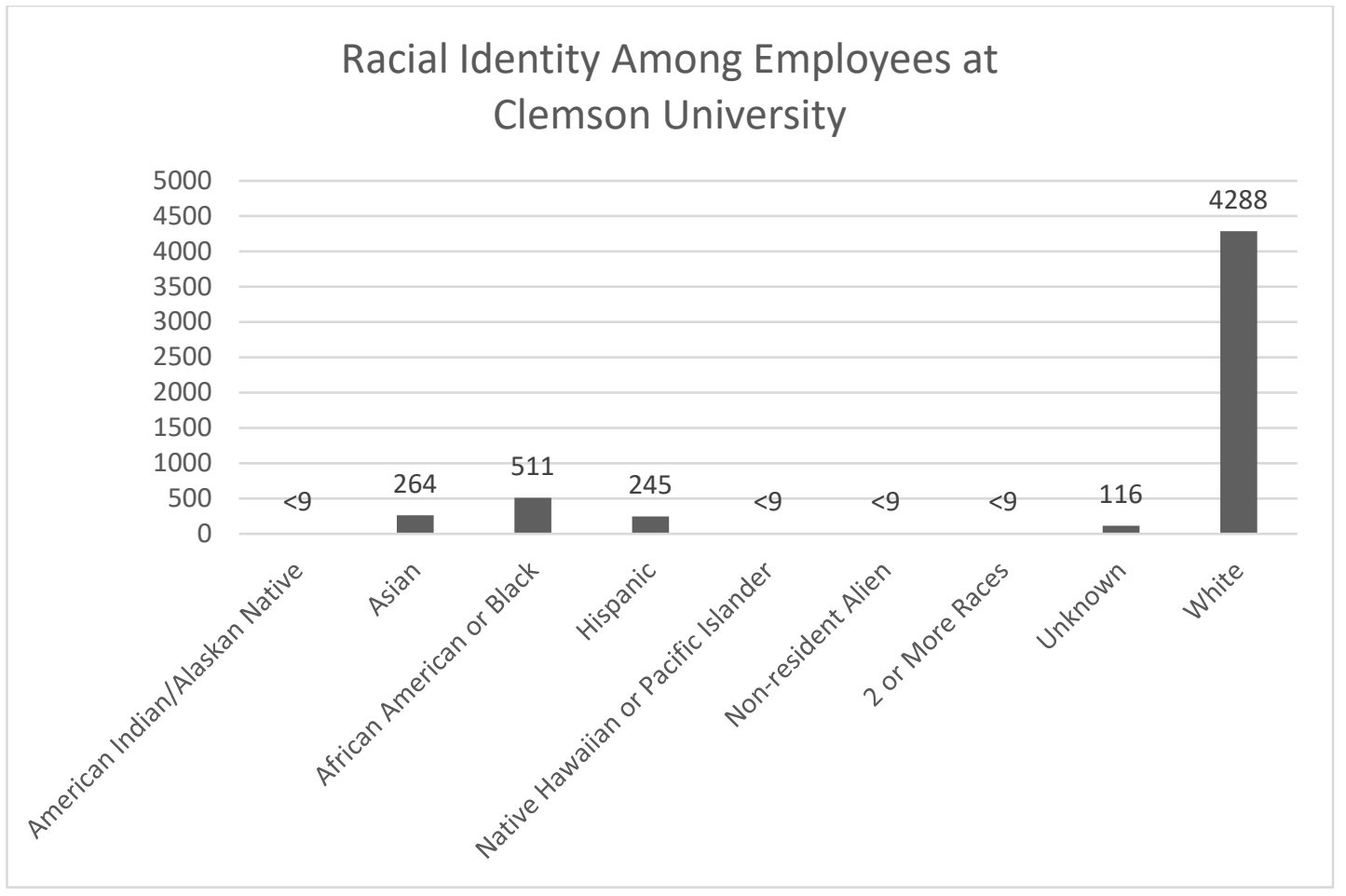

Figure 3: Racial Identity Among Employees at Clemson University Libraries

\section{Racial Identity Among Employees at Clemson University Libraries}

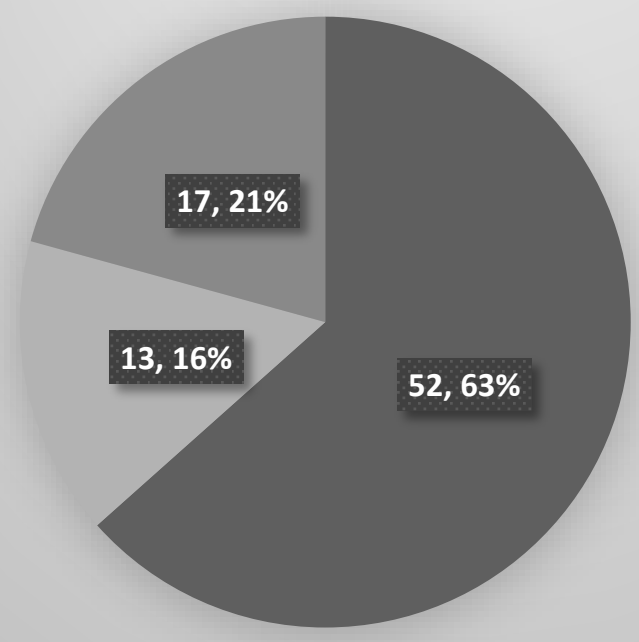

White

Non-white

Did not disclose 
Figure 4: Institutional Inspiration

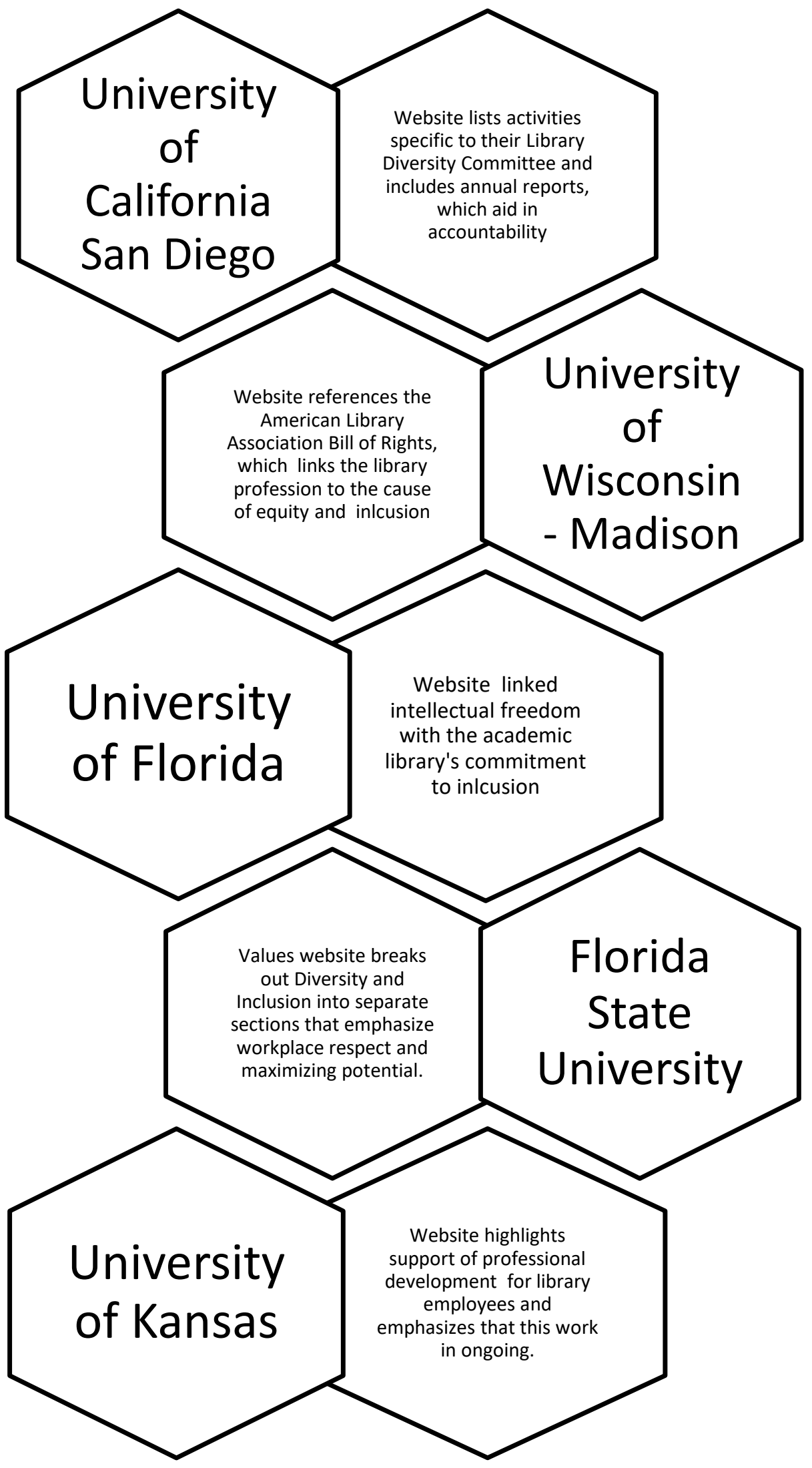

